\title{
Arginine, An Indispensable Amino Acid for Patients with Inborn Errors of Urea Synthesis
}

\author{
Saul W. Brusilow \\ Department of Pediatrics, The Johns Hopkins University School \\ of Medicine, Baltimore, Maryland 21205
}

bstract. The role of arginine as an essential amino was evaluated in four children with one of the deficiencies of carbamyl phosphate synthetase, ornithine transcarbamylase, argininosuccinate synthetase, and argininosuccinase. Within 15-68 h after arginine deprivation nitrogen accumulated as ammonium or glutamine or both, but glutamine was quantitatively the largest nitrogen accumulation product. Concomitantly plasma and urinary urea levels decreased. Resumption of arginine intake (or citrulline in the case of ornithine transcarbamylase deficiency) promptly led to correction of the hyperammonemia, hyperglutaminemia and hypoargininemia. Ornithine was an unsatisfactory substitute for arginine. Arginine deprivation did not interfere with carbamyl phosphate synthesis as manifested by orotic aciduria. It is concluded that arginine is an indispensable amino acid for children with inborn errors of ureagenesis and its absence results in the rapid onset of symptomatic hyperammonemia.

\section{Introduction}

In man the biosynthesis of both urea and arginine requires four enzymes in common; carbamyl phosphate synthetase (EC 2.7.2.2) (CPS), ${ }^{1}$ ornithine transcarbamylase (EC 2.1.3.3) (OTC), argininosuccinic acid synthetase (EC 6.3.4.5) (AS) and argininosuccinase (EC 4.3.2.1) (AL). Arginine should thus be an essential amino acid for infants with inborn errors of ureagenesis (apart from arginase deficiency) unless there is an unknown pathway for arginine biosynthesis. However, data supporting

\section{Received for publication 10 January 1984 and in revised form 30 July} 1984.

1. Abbreviations used in this paper: $\mathrm{AL}$, argininosuccinase; $\mathrm{AS}$, argininosuccinic acid synthetase; CPS, carbamyl phosphate synthetase; OTC, ornithine transcarbamylase.

J. Clin. Invest.

(c) The American Society for Clinical Investigation, Inc. $0021-9738 / 84 / 12 / 2144 / 05 \quad \$ 1.00$

Volume 74, December 1984, 2144-2148 this prediction have not been reported. Furthermore, the time course of the effect of arginine deprivation on waste nitrogen metabolism is unknown. This study is designed to evaluate the role of arginine in such patients by substituting ornithine for arginine in approximately equimolar proportions to maintain an isonitrogenous intake (assuming that two of the nitrogen atoms of arginine are destined for urea synthesis and excretion). Provision of ornithine also assures that residual ureagenesis (if any) will not be limited by lack of ornithine. Previous studies of arginine deprivation in children showed no change in nitrogen balance (1).

Management of inborn errors of ureagenesis studied here relied upon activation of nonureagenic pathways of waste nitrogen excretion as well as manipulation of dietary nitrogen, each aspect tailored to the specific characteristics of each enzyme deficiency $(2,3)$. For patients deficient in CPS or OTC, administration of sodium benzoate stimulates hippurate synthesis and excretion, which serves as a urinary waste nitrogen product containing one waste nitrogen atom per molecule. For patients with deficiencies of AS and AL dietary arginine supplementation promotes the synthesis of citrulline and argininosuccinate, which respectively serve as urinary waste nitrogen products. The former contains one, and the latter two, effective urinary waste nitrogen atoms per molecule when derived from dietary arginine. The patient with AS deficiency reported here also received sodium benzoate.

Dietary measures for the study patients deficient in CPS and OTC included a milk protein intake of $0.7 \mathrm{~g} \cdot \mathrm{kg}^{-1} \mathrm{~d}^{-1}$ supplemented with $0.7 \mathrm{~g} \cdot \mathrm{kg}^{-1} \mathrm{~d}^{-1}$ of an essential amino acid mixture (2) and $1 \mathrm{mmol} \cdot \mathrm{kg}^{-1} \mathrm{~d}^{-1}$ of arginine (free base). For the patient deficient in AS a similar diet was given with a larger arginine supplement $\left(3-4 \mathrm{mmol} \cdot \mathrm{kg}^{-1} \mathrm{~d}^{-1}\right)$. For the patient deficient in AL a low protein diet $\left(1.5 \mathrm{~g} \cdot \mathrm{kg}^{-1} \mathrm{~d}^{-1}\right)$ was supplemented with $3-4 \mathrm{mmol} \cdot \mathrm{kg}^{-1} \mathrm{~d}^{-1}$ arginine. ${ }^{2}$ Total nitrogen intakes from these three dietary protocols were, respectively, 217,245 , and $436 \mathrm{mg} \cdot \mathrm{kg}^{-1} \mathrm{~d}^{-1}$. Supplementary calories to

2. Since this work was completed, the following modifications have been made in the therapeutic protocol: patients who are deficient in CPS, OTC, and AS receive both the sodium or calcium salts of benzoate and phenylacetate. Patients who are deficient in AS now receive all their dietary nitrogen from protein. Citrulline is supplied as a source of arginine in patients who are deficient in CPS and OTC. 
maintain intake $>120 \mathrm{cal} \cdot \mathrm{kg}^{-1} \mathrm{~d}^{-1}$ were supplied from nonnitrogenous sources.

\section{Methods}

Plasma ammonium and amino acid levels were measured as previously described $(2,3)$. Plasma and urinary urea were measured by the method Chaney and Marbach (4). Creatinine was measured by the Jaffe reaction after absorption on Lloyd's reagent (5). Urinary orotate was measured as described by Bachmann and Colombo (6).

Experimental protocol. Four patients were studied, one each with a complete deficiency of one of CPS, OTC, AS, and AL. Except for the OTC deficient patient (who had two male siblings die in the neonatal period and who was rescued from neonatal hyperammonemic coma), the others have been reported previously (7) (patients 1, 13, and 19). Apart from the patient deficient in $\mathrm{AL}$, all were maintained on sodium benzoate $\left(250 \mathrm{mg} \cdot \mathrm{kg}^{-1} \mathrm{~d}^{-1}\right)$.

After a control period, ornithine acetate was substituted in approximately in equimolar amounts for arginine (free base) except in the AS-deficient patient, where arginine intake was maintained at a dose of $\sim 0.2 \mathrm{mmol} \cdot \mathrm{kg}^{-1} \mathrm{~d}^{-1}$. The substitution period varied depending upon patient response and was terminated by resumption of arginine intake or, in the patient with OTC deficiency, by the addition of citrulline as a source of arginine. Plasma levels of ammonium, urea (omitted in the CPS-deficient patient) glutamine, arginine, and ornithine were measured as were urinary excretion of urea nitrogen, creatinine, and orotate.

These studies were approved by the institutional review board of The Johns Hopkins Medical Institutions and informed parental consent was obtained. Sodium benzoate and citrulline are Investigational New Drugs approved for human use by The United States Food and Drug Administration.

\section{Results}

Fig. 1 shows the results in a 3-mo-old infant with CPS deficiency. Within $24 \mathrm{~h}$ after the arginine supplement was discontinued his plasma ammonium and glutamine levels (micromolar) increased from 30 (normal limits $<35$ ) and 675 (normal limits $483 \pm 86$ ) to 180 and 1,812 , respectively. The hyperammonemia that was accompanied by lethargy and vomiting promptly responded to intravenous arginine $\mathrm{HCl}$ and sodium benzoate. Plasma levels of arginine and ornithine (normal limits $85 \pm 26$ and $43.8 \pm 11$ respectively) changed little. Urinary urea nitrogen excretion fell from $1.6 \mathrm{mg}$ to $0.6 \mathrm{mg}$ nitrogen/mg creatinine (normal range for fasting infants is 10 $30 \mathrm{mg}$ [8]). Not shown in Fig. 1 are urinary orotate levels that remained normal $(<0.01 \mathrm{mg} / \mathrm{mg}$ creatinine) and plasma levels of alanine, proline, and glutamate that also were unchanged.

Fig. 2 shows the results in a 1-mo-old patient with OTC deficiency. Within $15 \mathrm{~h}$ after arginine was discontinued the plasma ammonium and glutamine levels (micromolar) increased from 8 and 210 to 82 and 1,064 , respectively. The hyperammonemia was associated with the onset of vomiting although he remained alert throughout the study. Unlike the CPS deficient patient the plasma arginine level decreased from 34 to $11 \mu \mathrm{M}$. No pattern of urinary urea nitrogen excretion
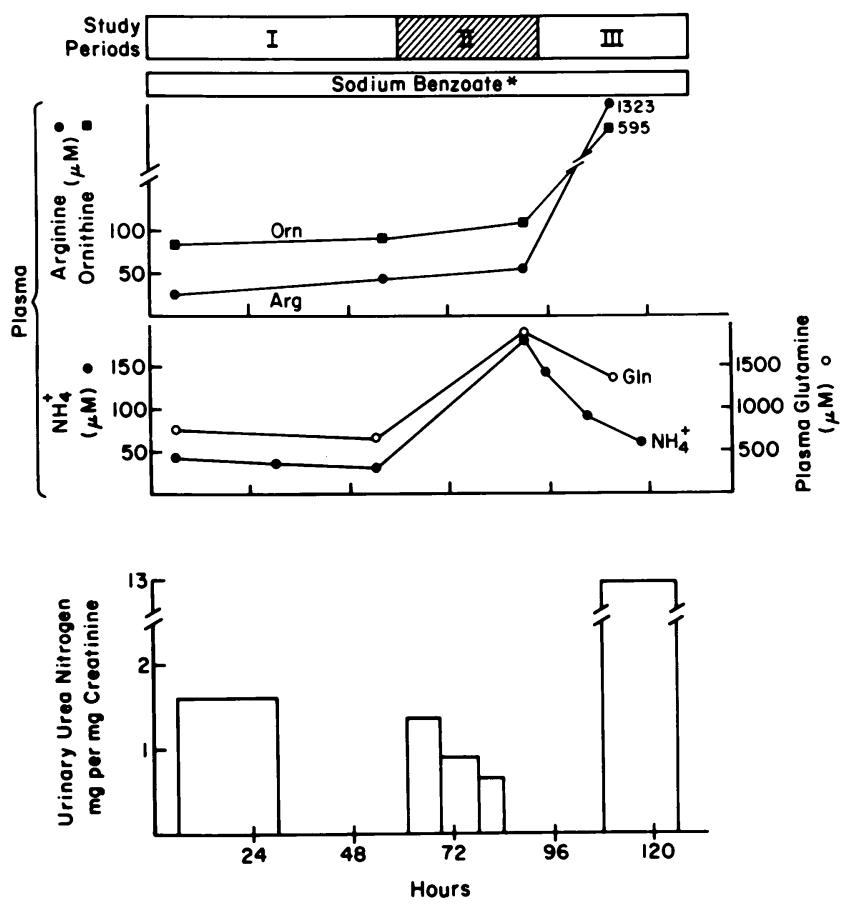

Figure 1. The effect of discontinuing arginine supplements in a 3-mo-old male with carbamyl phosphate synthetase deficiency. Study periods: I, oral arginine (free base), $1 \mathrm{mmol} \cdot \mathrm{kg}^{-1} \mathrm{~d}^{-1}$; II, oral ornithine acetate, $1 \mathrm{mmol} \cdot \mathrm{kg}^{-1} \mathrm{~d}^{-1}$; III, intravenous arginine $\mathrm{HCl}, 2$ $\mathrm{mmol} \cdot \mathrm{kg}^{-1}$, for $1 \mathrm{~h}$, followed by oral arginine, $1 \mathrm{mmol} \cdot \mathrm{kg}^{-1} \mathrm{~d}^{-1}$. *Sodium benzoate $\left(250 \mathrm{mg} \cdot \mathrm{kg}^{-1} \mathrm{~d}^{-1}\right)$ was given orally except during period III, when it was given intravenously $\left(250 \mathrm{mg} \cdot \mathrm{kg}^{-1}\right.$ for $\left.1 \mathrm{~h}\right)$ followed by oral benzoate $\left(250 \mathrm{mg} \cdot \mathrm{kg}^{-1} \mathrm{~d}^{-1}\right)$. Abbreviations: Arg, arginine; Gln, glutamine; Orn, ornithine. Normal plasma values $(\mu \mathrm{M}): \mathrm{NH}_{4}^{+},<35$; $\mathrm{Arg}, 85 \pm 26$; Gln, 483 \pm 86 ; Orn, 43.8 \pm 11 , and Urea (mM) 2.2-8.2. Normal urine values (milligram per milligram creatinine): urea nitrogen, 10-30; orotic acid, $<0.01$.

was demonstrated. Urinary orotate excretion increased dramatically to $0.67 \mathrm{mg} / \mathrm{mg}$ creatinine $30 \mathrm{~h}$ after arginine was withdrawn. The addition of citrulline resulted in a prompt return of the plasma ammonium, arginine, and glutamine levels toward normal as well as a decrease in urinary orotate. Not shown in Fig. 2 are alanine levels that increased from 280 to $488 \mu \mathrm{M}$ after arginine withdrawal and decreased to 237 when citrulline was added. Proline and glutamate levels were unchanged.

Fig. 3 shows the results in a 1-mo-old with AS deficiency. This study departed from the protocol described in Figs. 1 and 2 in that $0.2 \mathrm{mmol} \cdot \mathrm{kg}^{-1} \mathrm{~d}^{-1}$ of arginine remained in the supplement as a precautionary measure. After arginine supplements were discontinued plasma ammonium levels (micromolar) showed little change rising from 21 to 35 within $68 \mathrm{~h}$, whereas plasma glutamine levels (micromolar) increased from 242 to 695 during the same period. The plasma arginine level, which was elevated at $322 \mu \mathrm{M}$ decreased to 10 over the same 


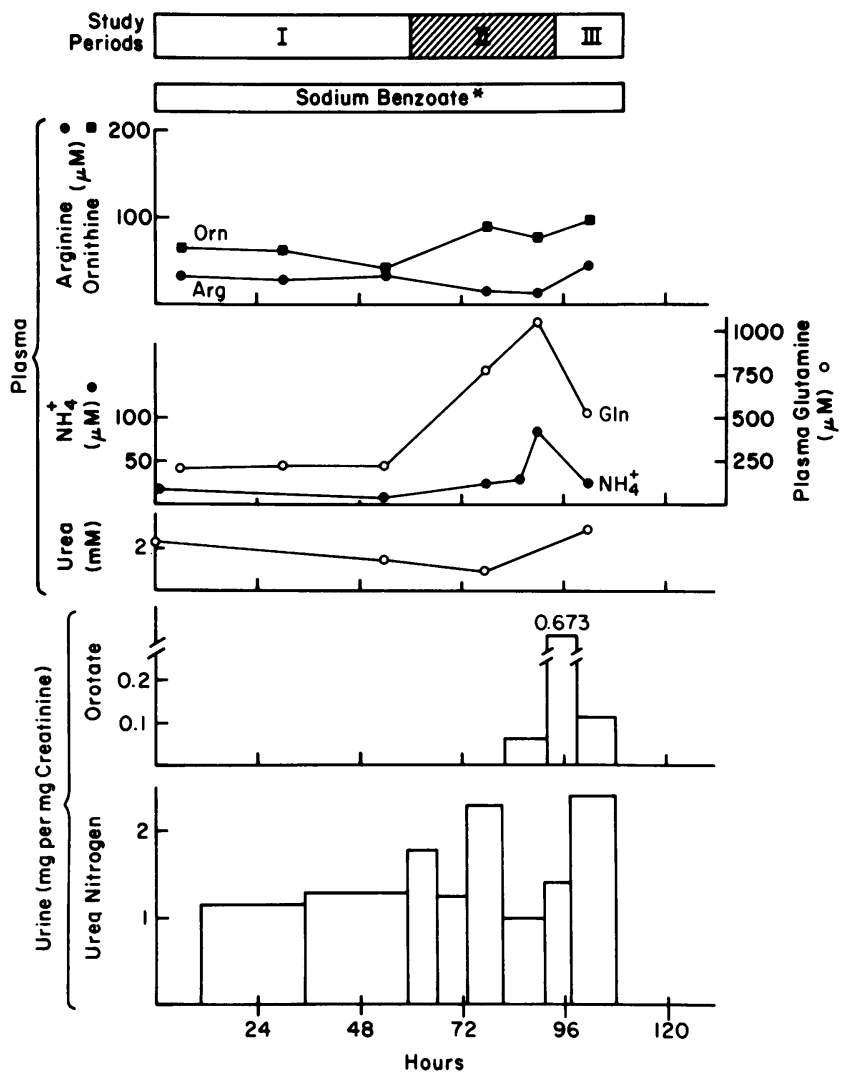

Figure 2. The effect of discontinuing arginine supplements in a 1mo-old male infant with ornithine transcarbamylase deficiency. Study periods: I, oral arginine (free base), $1 \mathrm{mmol} \cdot \mathrm{kg}^{-1} \mathrm{~d}^{-1}$; II, oral ornithine acetate, $1 \mathrm{mmol} \cdot \mathrm{kg}^{-1} \mathrm{~d}^{-1}$; III, oral citrulline, $1 \mathrm{mmol} \cdot \mathrm{kg}^{-1} \mathrm{~d}^{-1}$. *Sodium benzoate $\left(250 \mathrm{mg} \cdot \mathrm{kg}^{-1} \mathrm{~d}^{-1}\right)$ was given orally. See legend to Fig. 1 for abbreviations and normal values. period while urinary urea excretion fell to nearly zero. Restoration of arginine to the diet at a dose of $1.7 \mathrm{mmol} \cdot \mathrm{kg}^{-1} \mathrm{~d}^{-1}$ (with ornithine acetate maintained $1.7 \mathrm{mmol} \cdot \mathrm{kg}^{-1} \mathrm{~d}^{-1}$ ) resulted in a prompt decrease in the plasma glutamine level and an increase in the plasma arginine level and urinary urea nitrogen excretion. Not shown in Fig. 3 are alanine levels, which increased from 167 to 449 after arginine withdrawal and decreased to 264 when arginine therapy was resumed. Glutamate levels also increased (44-130), whereas proline levels were unchanged. Also not shown in Fig. 3 is the urinary orotate excretion, which remained normal throughout the study.

Fig. 4 shows the effect of interruption of arginine intake in a 2-yr-old patient with AL deficiency. Within $22 \mathrm{~h}$ the plasma ammonium and glutamine levels increased from 38 and 589 to 182 and $887 \mu \mathrm{M}$, respectively, while the arginine level decreased from 117 to $28 \mu \mathrm{M}$. During the hyperammonemic period he was lethargic and irritable. Urinary urea nitrogen decreased from 2.2 to $0.68 \mathrm{mg} / \mathrm{mg}$ creatinine. Urinary orotate excretion remained below $0.01 \mathrm{mg} / \mathrm{mg}$ creatinine until $48 \mathrm{~h}$ after arginine was discontinued, at which time it increased to 0.048 . The hyperammonemia increased to 192 despite an intravenous dose of sodium benzoate $\left(250 \mathrm{mg} \cdot \mathrm{kg}^{-1}\right.$ over $1 \mathrm{~h}$ ) but promptly responded to intravenous arginine $\mathrm{HCl}(4 \mathrm{mmol} /$ $\mathrm{kg}$ over $1 \mathrm{~h}$ followed by $3 \mathrm{mmol} \cdot \mathrm{kg}^{-1} \mathrm{~d}^{-1}$ ). Not shown in Fig. 4 are plasma alanine levels that increased slightly from 242 to $390 \mu \mathrm{M}$ after arginine withdrawal and decreased to $267 \mu \mathrm{M}$ after arginine was restored. Plasma glutamate levels increased slightly but proline levels were unchanged during the study.

\section{Discussion}

Nitrogen accumulation. Withdrawal of supplemental dietary arginine led to nitrogen accumulation as ammonium or glu-

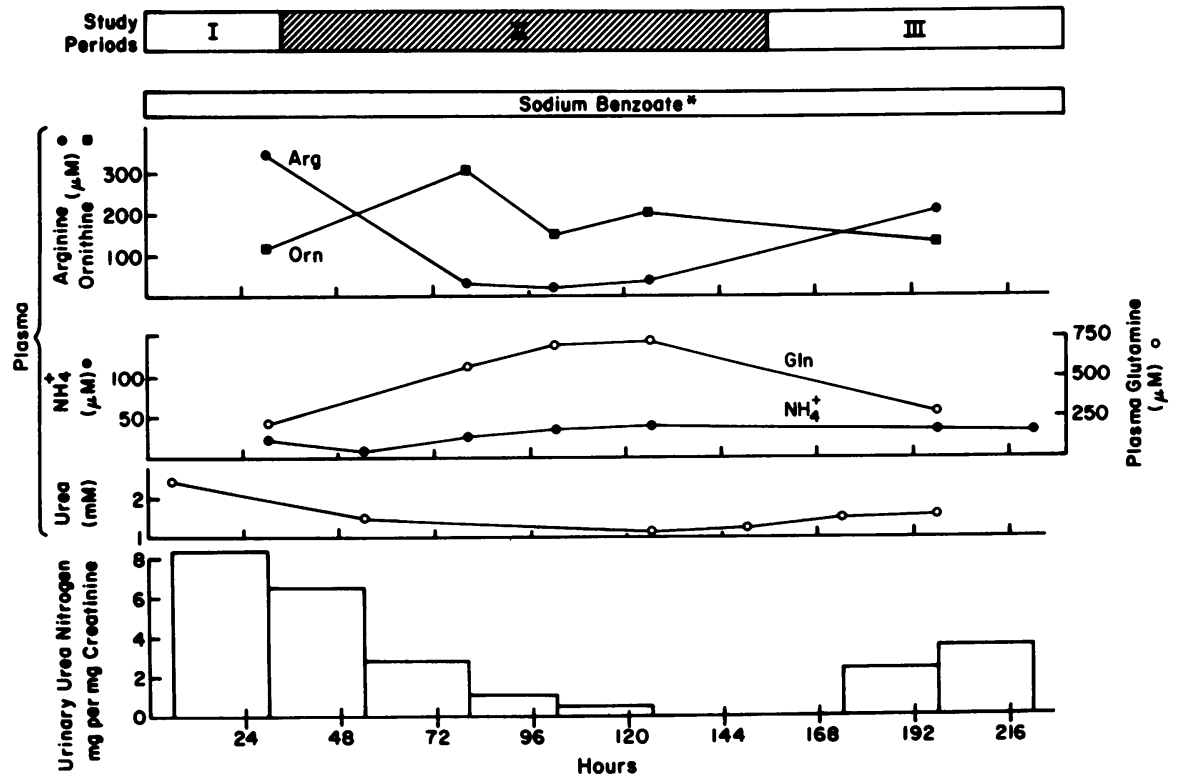

Figure 3. The effect of discontinuing arginine supplements in a 1-mo-old female with argininosuccinic acid synthetase deficiency. Study periods: 1 , oral arginine (free base), $4.5 \mathrm{mmol} \cdot \mathrm{kg}^{-1} \mathrm{~d}^{-1}$; II, oral ornithine acetate, $3.3 \mathrm{mmol} \cdot \mathrm{kg}^{-1} \mathrm{~d}^{-1}$; and oral arginine (free base), $0.2 \mathrm{mmol} \cdot \mathrm{kg}^{-1} \mathrm{~d}^{-1}$; III, oral arginine (free base) and ornithine acetate each at $1.7 \mathrm{mmol} \cdot \mathrm{kg}^{-1} \mathrm{~d}^{-1}$. ${ }^{*} \mathrm{So}-$ dium benzoate $\left(250 \mathrm{mg} \cdot \mathrm{kg}^{-1} \mathrm{~d}^{-1}\right)$ was given orally. See legend to Fig. 1 for abbreviations and normal values. 


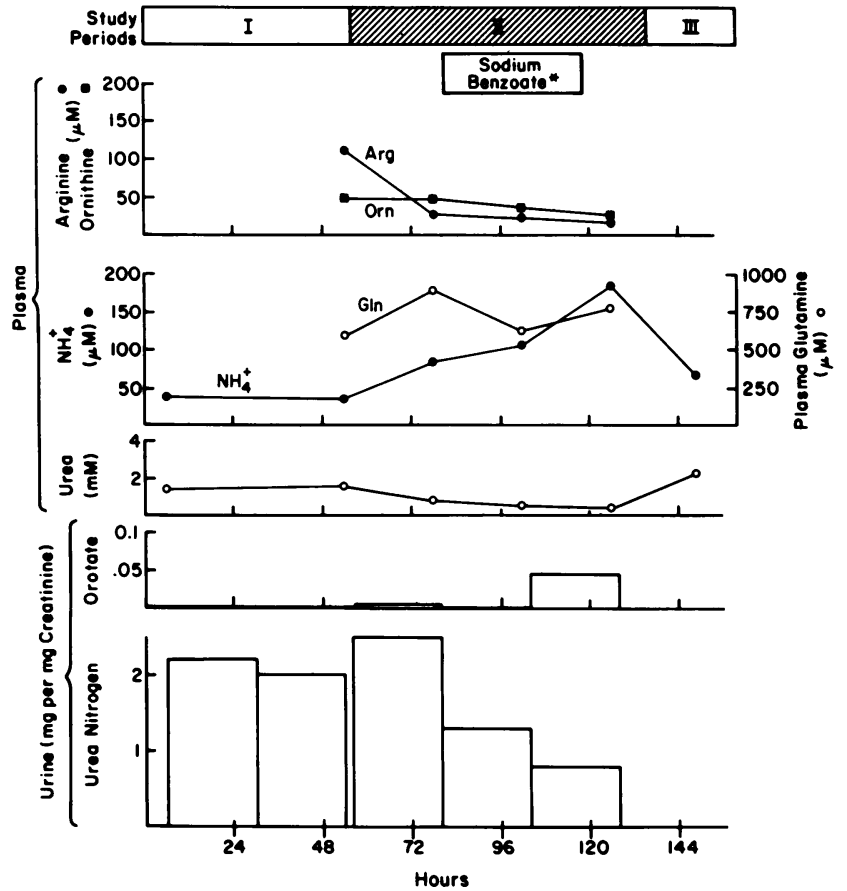

Figure 4. The effect of discontinuing arginine supplements in a 2-yrold male with argininosuccinase deficiency. Study periods: I, oral arginine (free base), $2.5 \mathrm{mmol} \cdot \mathrm{kg}^{-1} \mathrm{~d}^{-1}$; II, oral ornithine acetate, 2.5 $\mathrm{mmol} \cdot \mathrm{kg}^{-1} \mathrm{~d}^{-1}$; III, intravenous arginine $\mathrm{HCl}, 4 \mathrm{mmol} \cdot \mathrm{kg}^{-1}$ for $1 \mathrm{~h}$ followed by $4 \mathrm{mmol} \cdot \mathrm{kg}^{-1} \mathrm{~d}^{-1}$. *Sodium benzoate was given orally $\left(250 \mathrm{mg} \cdot \mathrm{kg}^{-1} \mathrm{~d}^{-1}\right)$ between the $81 \mathrm{st}$ and 118 th $\mathrm{h}$ of the study and intravenously $\left(205 \mathrm{mg} \cdot \mathrm{kg}^{-1}\right.$ over $1 \mathrm{~h}$ ) during the $109 \mathrm{th} \mathrm{h}$ of the study. See legend to Fig. 1 for abbreviations and normal values.

tamine or both in all four patients tested. Plasma ammonium levels increased in three patients (Figs. 1, 2, and 4), all of whom were symptomatic with one or more clinical manifestation of hyperammonemia; vomiting, lethargy, or irritability. The hyperammonemia promptly responded to repletion of arginine. That arginine synthesis from citrulline is unimpaired in OTC deficiency is shown in Fig. 2 where citrulline administration resulted in a decrease in the plasma ammonium and glutamine levels and an increase in arginine levels as promptly as did arginine administration in the CPS deficient patient (Fig. 1). Citrulline as a substitute for arginine would not be effective in those diseases where the pathway for citrulline to arginine was interrupted; i.e., deficiencies of AS and AL.

The largest amount of nitrogen accumulation in response to the withdrawal of arginine resided in glutamine, the plasma level of which increased by $250-500 \%$. If similar percentage increases occurred in intracellular glutamine levels (which normally are $\sim 30$-fold greater (9) than plasma levels) the amount of nitrogen accumulated could be as high as $256 \mathrm{mg}$. $\mathrm{kg}^{-1}$ (assuming the plasma level increased by $750 \mu \mathrm{M}$ as in Fig. 2 and intracellular and extracellular water to be 40 and
$20 \%$ of the body weight, respectively). In all cases the glutamine level promptly returned toward normal when arginine or citrulline was restored to the diet.

Nitrogen also accumulated as alanine and glutamate, but these changes were relatively small as compared with glutamine.

Indirect evidence of nitrogen accumulation as carbamyl phosphate in the OTC deficient (Fig. 2) and AL deficient (Fig. 4) patient may be adduced from the marked increase and subsequent decrease of orotic aciduria as arginine was withdrawn and subsequently restored. Orotic aciduria is ordinarily a constant finding in hyperammonemic OTC deficient patients but has only rarely been described in patients with AL deficiency (10). The lack of an orotic aciduric response of the AS-deficient patient is compatible with the absence of hyperammonemia, which is presumably a consequence of the small arginine supplement she received.

Plasma arginine, urea, and ornithine levels. In three of the four patients plasma arginine levels decreased immediately after its withdrawal and increased after its restoration. The mechanism that maintained the plasma arginine in the CPSdeficient patient is unclear although it is possible that arginine residues derived from proteolysis were produced at a rate similar to arginine degradation.

That exogenous arginine plays a major role in sustaining the plasma urea concentration in patients with inborn errors of ureagenesis is shown in Figs. 1-4 where the plasma urea levels that started at the lower limits of normal decreased even further after arginine was withdrawn. The onset of hyperammonemia and its therapy (Figs. 1, 2, and 4) prevented an attempt to establish a minimum plasma urea level.

Plasma ornithine levels increased in the AS-deficient patient (Fig. 3) but were unchanged in the other three.

Urinary urea excretion, which was very low under control conditions, decreased as expected when arginine was withdrawn except in the OTC deficient patient who, at the time his plasma urea level was lowest, demonstrated a variable urinary urea excretion. Conceivably his enzyme defect may be a variant that responded to increased levels of intramitochondrial carbamyl phosphate.

Mechanism of action. There are two possible explanations for these findings. Because patients with these defects in urea synthesis have a similar defect in arginine synthesis it is likely that arginine deprivation leads to net proteolysis because the normal protein degradation-resynthesis cycle is interrupted. Protein synthesis will be limited both by defective arginine synthesis and its continued degradation. This process is analogous to the sequence of events that occurs when a single essential amino acid is eliminated from the diet in children (1) or adults (11). In normal subjects evidence of protein breakdown in excess of synthesis is manifested by increasing urea appearance in plasma and urine. In these four children who cannot synthesize urea from protein breakdown products, the nitrogen so produced accumulates as glutamine as shown 
in Figs. 1-4. As described earlier it is conceivable that as much as $256 \mathrm{mg} \cdot \mathrm{kg}^{-1}$ of glutamine nitrogen could accumulate within $24 \mathrm{~h}$. Although possibly an overestimate this would represent $1.5 \mathrm{~g} \cdot \mathrm{kg}^{-1} \mathrm{~d}^{-1}$ of proteolysis.

A second effect of arginine withdrawal may be related to its role as an activator of $\mathrm{N}$-acetylglutamate synthetase (12). To the extent that there is residual activity of a defective urea cycle enzyme in these patients, a reduction in carbamyl phosphate synthetase activity consequent to $\mathrm{N}$-acetylglutamate underproduction would have an adverse effect on whatever low urea synthetic capacity may be present. However, it is unlikely that arginine deficiency in these cases exerted such an effect because two patients demonstrated an increase in urinary orotate; evidence suggesting that substantial synthesis of carbamyl phosphate did take place.

Notwithstanding the above explanations, the hyperammonemia, hyperglutaminemia, and orotic aciduria that occurred in the AL-deficient patient remain puzzling because maintenance of ornithine supply should have supported waste nitrogen excretion as argininosuccinate to the same extent as did arginine. The maintenance of plasma ornithine levels by ornithine substitution would seem to rule out the possibility that intramitochondrial ornithine deprivation could account for reduced argininosuccinate or residual urea synthesis. Although intramitochondrial ornithine degradation via ornithine aminotransferase occurs in extrahepatic tissues, (13) there is little reason to expect organ-specific extracellular-mitochondrial ornithine transport that would preferentially divert ornithine from the liver.

Unexamined in this report is the role of arginine as an amidino donor in the biosynthesis of guanidoacetate, creatine or other such compounds.

Perhaps the most important clinically relevant finding described here is the rapidity with which infants with inborn errors of urea synthesis develop symptomatic hyperammonemia. Such infants clearly require medical attention whenever the intake of arginine or other medications are interrupted or whenever the early signs of hyperammonemia (vomiting, irritability or lethargy) occur.

These results show that arginine is an essential amino acid in children with inborn errors of urea synthesis; therefore, dietary arginine (or citrulline in patients with deficiencies of CPS or OTC) supplementation is necessary.

\section{Acknowledgments}

I wish to thank the following for their assistance; Ellen Gordes, Robin Gurganus, Bernadine Peters and her nursing staff, Drs. David Valle, George Thomas, Mark Batshaw, and Lewis Waber.

This work was supported by grants R01-HD11134 and M01-RR0052 from the National Institutes of Health, and by the Kettering Family Foundation.

\section{References}

1. Nakagawa, I., T. Takahashi, T. Suzuki, and K. Kobayashi. 1963. Amino acid requirements of children: Minimal needs of tryptophan, arginine and histidine based on nitrogen balance method. J. Nutr. 80:305-310.

2. Brusilow, S., J. Tinker, and M. L. Batshaw. 1980. Amino acid acylation: a mechanism of nitrogen excretion in inborn errors of urea synthesis. Science (Wash. DC). 207:659-661.

3. Brusilow, S., M. L. Batshaw, and L. Waber. 1982. Neonatal hyperammonemic coma. Adv. Pediatr. 29:69-103.

4. Chaney, A., and E. P. Marbach. 1962. Modified reagents for determination of urea and ammonia. Clin. Chem. 8:130-132.

5. Van Pilsum, J. F. 1959. Determination of creatinine and related guanidium compounds. Methods Biochem. Anal. 7:193-215.

6. Bachmann, C., and J. P. Colombo. 1980. Determination of orotic acid in children's urine. J. Clin. Chem. Clin. Biochem. 18:293295.

7. Batshaw, M. L., S. Brusilow, L. Waber, W. Blom, A. M. Brubakk, B. Burton, H. Cann, D. Kerr, P. Mamunes, D. Myerberg, and I. Schafer. 1982. Treatment of inborn errors of urea synthesis. $N$. Engl. J. Med. 306:1387-1392.

8. Dugdale, A. E., and E. Edkins. 1964. Urinary urea/creatinine ratios in healthy and malnourished children. Lancet. I:1062-1064.

9. Bergström, J., P. Furst, L. O. Norée, and E. Vinnars. 1964. Intracellular free amino acid concentration in human muscle. J. Appl. Physiol. 36:693-697.

10. Bachmann, C., and J. P. Colombo. 1980. Diagnostic value of orotic acid excretion in heritable disorders of the urea cycle and in hyperammonemia due to organic acidurias. Eur. J. Pediatr. 134:109113.

11. Rose, W. C., J. E. Johnson, and W. J. Haines. 1950. The amino acid requirements of man. The role of valine and methionine. J. Biol. Chem. 182:541-556.

12. Shigesada, K., K. Aoyagi, and M. Tatibana. 1978. Role of acetylglutamate in ureotelism. Eur. J. Biochem. 85:385-391.

13. Peraino, C., and H. C. Pitot. 1963. Ornithine transaminase in the rat. I. Assay and some general properties. Biochim. Biophys. Acta. 73:222-231. 